\title{
Hepatitis B virus infection among people who use drugs in Iran: a systematic review, meta-analysis, and trend analysis
}

\author{
Yasna Rostam-Abadi ${ }^{1}$, Hossein Rafiemanesh², Jaleh Gholami ${ }^{{ }^{*}}$ (D), Behrang Shadloo ${ }^{1}$, \\ Masoumeh Amin-Esmaeili, ${ }^{1,3}$ and Afarin Rahimi-Movaghar ${ }^{1}$
}

\begin{abstract}
Background: People who use drugs (PWUD) are considered as one of the main at-risk populations for Hepatitis B virus (HBV) infection. We conducted a systematic review on the prevalence of HBV infection among PWUD in Iran.

Methods: Consistent with PRISMA guideline, international (Medline, Web of Science, Scopus, and Embase) and national (Scientific Information Database) databases were searched using a comprehensive search strategy up to September 2019. The retrieved records were reviewed, and experts were contacted for unpublished studies. Studies on Iranian PWUD reporting HBV surface Antigen (HBsAg) prevalence among people who inject drugs (PWID) and non-injecting PWUD were included. HBsAg prevalence was pooled for PWID and non-injecting PWUD and for other subgroups using random-effects model meta-analysis. The trend of HBV prevalence over time was investigated using meta-regression analysis.
\end{abstract}

Results: Overall, 35 studies reported data on HBV infection among PWID (33 studies) and non-injecting PWUD (11 studies). The pooled prevalence of HBsAg among PWID was 4.8\% (95\% Cl 3.7-6.2). The only risk factor significantly associated with the odds of positive HBsAg in PWID was the previous history of imprisonment (OR 1.72, 95\% Cl 1.292.30, $p$ value $=0.000$ ). The pooled estimate of HBsAg among non-injecting PWUD was $2.9 \%(95 \% \mathrm{Cl} 2.5-3.2)$. Time trend analyses showed significant decrease in HBV prevalence among PWID reaching from $8.2 \%(95 \% \mathrm{Cl} 3.9-16.5)$ in $2004-2006$ to $3.1 \%(95 \% \mathrm{Cl} 2.3-4.1)$ in 2016 and later $(b=-0.07 ; p$ value $=0.05)$. No significant trend was detected for non-injecting PWUD.

Conclusion: The prevalence of HBV infection among non-injecting PWUD and even PWID was not considerably higher than the Iranian general population. This might be the result of extensive harm reduction interventions in Iran. However, it seems that there are subgroups of PWID, who do not adequately benefit from existing harm reduction interventions. Future programs should more specifically target these high-risk groups.

Keyword: Hepatitis B, Blood-borne infections, Substance use, Addiction, Harm reduction, Injecting drug use, Epidemiology, Iran

*Correspondence: zh_gholami@farabi.tums.ac.ir

${ }^{1}$ Iranian National Center for Addiction Studies (INCAS), Tehran University of Medical Sciences, No. 486, South Karegar Ave., 1336616357 Tehran, Iran Full list of author information is available at the end of the article

\section{Introduction}

Hepatitis B virus (HBV), a vaccine-preventable infection, remains one of the leading causes of acute and chronic liver diseases [1]. In 2017, there were 13.8 million new cases of chronic HBV globally [2]. The resulting cirrhosis and hepatocellular carcinoma were the main contributing factors to HBV burden. In 2017, 
HBV-related DALY and mortality rate were estimated as 107.2 years and 3.7 per 100,000 in Iran, respectively [2].

Hepatitis B is one of the main infectious diseases among people who use drugs (PWUD). There are several reasons why PWUD are considered more vulnerable to HBV. Needle sharing is one of the major routes of transmission among people who inject drugs (PWID) [3]. Substance use contributes to other certain vulnerabilities [4] such as homelessness [5, 6], incarceration [7], and unsafe sexual contacts [1]. In addition, this population has limited access to health services required for timely prevention, diagnosis, and treatment [3]. The World Health Organization (WHO) considers PWUD as one of the main adult target populations in its strategy for ending HBV [1]. Promoting harm reduction services is introduced as one of the five core interventions for combating viral hepatitis, including HBV; alongside with vaccination, prevention of mother-to-child transmission, safety of medical interventions, and treatments programs [1]. The impact targets for 2030 by the WHO are $90 \%$ of reduction in new chronic cases of $\mathrm{HBV}$ and $65 \%$ reduction in attributed mortality [1].

Substance use has been a public health issue for decades in Iran [8]. The Iranian National Mental Health Survey (IranMHS) estimated the prevalence of any substance use disorder to be $2.8 \%$ in the Iranian general population [9]. Although it was previously estimated that more than $20 \%$ of PWUD had used drugs through injection in the last 12 months [10], recent studies have shown that the figure has decreased to about $3 \%[11,12]$. In Iran, drug use and injecting drug use are known as the main risk factors for HIV and HCV [13-17]; therefore, the country has adopted extensive harm reduction measures to control blood-borne infections among PWID for more than a decade.

HBV prevalence among PWUD has been assessed in many studies in Iranian population, and the results were quite different. In addition, HBV prevalence among PWID was assessed in a global systematic review. The provided estimate for $\mathrm{HBV}$ infection among Iranian PWID was considerably lower than the corresponding global (9\%) and regional Figures (8.1\%). However, this was not the case for HIV and HCV estimates [4]. Therefore, in order to provide a more detailed picture of HBV among PWUD in Iran, we conducted a systematic review on all studies providing the prevalence of HBV surface antigen (HBsAg) among both PWID and non-injecting PWUD, according to the socio-demographic characteristics, recruitment settings, high-risk behaviours, and geographical distribution. HBsAg, a surface protein, can be detected in both acute and chronic HBV infection, also indicating that the individual is infectious [18]. We also investigated the trend of changes in HBV prevalence among PWID and non-injecting PWUD over time.

\section{Methods \\ Search strategy and selection criteria}

The method used in this study is in accordance with the PRISMA guideline. For finding published studies, we searched international (Medline, Web of Science, Scopus, and Embase) and Iranian (Scientific Information Database-SID) bibliometric databases using a comprehensive search strategy in September 2019. Search strategy terms were categorized in four groups and combined using Boolean operators: (1) keywords related to Iran, including names of cities, provinces, and major universities in Iran; (2) the names of substances used in Iran and terms related to drug use or drug use disorders; (3) terms related to hepatitis and HIV. No restrictions on publication date and language of full text were applied. We completed our search by reviewing the references of the retrieved studies (backward citation tracking) and contacting experts in this field in order to access unpublished studies.

Studies were included if they: (1) were cross-sectional or cohort studies; (2) were on human subjects; (3) had been done on Iranian population; (4) were conducted on a target population of those with drug use or drug use disorders; (5) had assessed HBsAg prevalence (acute or chronic infection); (6) provided HBV or any index of HBV prevalence by injecting and non-injecting drug use group; and (7) had not recruited the study samples from infectious disease wards or HIV treatment and care centres. Due to the higher prevalence of infectious diseases in those admitted to infectious disease wards, the recruited sample would not be generalizable to PWUD and would be biased for estimating prevalence of HBV infection.

\section{Screening, data extraction, and quality assessment}

Screening of the identified documents was conducted in two stages: (1) screening of titles and abstracts to exclude irrelevant studies, and (2) assessing full texts for eligibility and inclusion criteria. If HIV or HCV prevalence and not HBV were stated in the abstract, the study was not excluded and full-text was reviewed as well. Both stages were done independently by two reviewers, and discrepancies between the reviewers were resolved by the third reviewer. The third reviewer also randomly checked both included and excluded records at each stage.

Two investigators independently extracted the data of included studies using a data extraction sheet. The extracted data of each study were checked by the two reviewers and discussed in case of disagreements. Data extraction sheet included bibliometric characteristics 
of the citation, year of study implementation, recruitment setting (prison, drug treatment centres, drop-in centres (DICs), etc.), study location (province), type of biological test for HBV, co-infection with HIV and HCV, route of drug use (injecting and non-injecting), definition of injecting drug use, sampling method, sample size, response rate, socio-demographic characteristics of the participants, history of high-risk behaviours, test results, and gender-specific data.

The quality of each study was assessed by an 8-item critical appraisal form, which was adapted from Joanna Briggs Institute (JBI) critical appraisal-checklist for crosssectional studies [19] in our research centre and has been used in similar studies [20]. If the data on four of these items (source of the sampling, subgroup analysis for gender, the type of laboratory test, and the year of the study) were not provided in the document, the authors were contacted for obtaining the related data. However, we reported that item as unfulfilled criteria in any case.

\section{Statistical analyses}

After entering the extracted data into an excel sheet, the $\mathrm{R}$ version 3.5.3 was used for statistical analyses. For estimating the pooled prevalence, we used the "metaprop" command and random-effects model for estimating the pooled prevalence of HBsAg, separately in PWID and non-injecting PWUD, and also in different subgroups of drug users according to socio-demographics, recruitment settings, and high-risk behaviours. The "metabin" command was used to calculate the DerSimonian-Laird pooled odds ratios for detecting association between various risk factors and HBsAg prevalence. The prevalence of HBsAg by province was presented in a map using the Arc GIS software version 10.5.

The number of studies conducted in each year was few; therefore, the prevalence of HBsAg for every three years was pooled and depicted in a line graph for showing the trend of prevalence over the years, and because of the nonlinear trend, we fitted meta-regression line for the segments to evaluate the significance of the line's slope. I-squared and Tau-squared statistics were applied for heterogeneity assessment. For heterogeneity interpretation, we used the following thresholds for I2 being $50-90 \%$ as may represent substantial heterogeneity; and $75-100 \%$ as considerable heterogeneity [21]. Meta-regression, using the "metareg" command, was performed perusing the source of heterogeneity among the included studies.

\section{Results}

\section{Study selection}

From a total of 2124 citations, 2121 records were found through electronic search in the online databases and three studies were identified through backward citation tracking and contacts with experts. After removing the duplicates, the title and abstract of the 1683 studies were screened. There were 136 records eligible for full-text review. Finally, 35 studies were included in the review (Fig. 1).

\section{Study characteristics}

A total of 35 studies conducted on 18,631 PWUD from the year 1990 to 2017 were included in this systematic review. Of those, 33 studies included PWID $(N=9805)$ and 11 studies included non-injecting PWUD $(N=8826)$. There were nine studies providing estimates for both PWID and non-injecting PWUD. The total sample size ranged from 29 to 4614 among different studies. Four studies were multi-provincial, and other studies were implemented in 13 different provinces. Based on the recruitment setting, studies fell into 6 different categories: prisons (15 studies, $N=12,900$ ), treatment centres (7 studies, $N=880$ ), communities (4 studies, $N=1882$ ), DICs (4 studies, $N=1003$ ), mixed settings (4 studies; $N=1840$ ), and hospital (one study; $N=126$ ). Eight studies defined injecting drug use as any lifetime injection. On the other hand, there were studies which defined injecting drug use as usual route of drug use $(N=1)$, current injecting drug use $(N=1)$, history of injection in the last month $(N=1)$, history of injection in the last two months $(N=1)$, history of injection in the last three months $(N=2)$, history of injection in the last 12 months $(N=2)$, or the presence of injection marks $(N=2)$. All these latter 10 studies were merged into a category of "current PWID" in the analyses. Fifteen (45.5\%) studies had not provided a definition for injecting drug use. Seven studies included both male and female PWUD, 13 studies only males, 2 studies only females, and in the other 13 studies, the gender of participants was not reported. The mean age of the subjects ranged from 28.8 to 48.2 years among the 16 studies providing this measure.

Any history of high-risk injection, such as ever sharing a needle, was present in $11.0 \%$ to $76.6 \%$ of the PWID among 15 different studies. Eight studies reported highrisk sexual behaviours among PWID with different definitions (men having sex with men, having a PWID partner, extramarital relationship, extramarital relationship without protection, sex exchange for money or drug, having sex with a sex worker, and multiple partners). High-risk sexual behaviours ranged from $5.0 \%$ to $43.1 \%$; no study assessed related measures among non-injecting PWUD. Eight studies reported a history of tattooing, ranging from $27.7 \%$ to $78.0 \%$ among PWID.

Excluding 14 studies recruiting their sample from prison, history of previous imprisonment ranged from $35.3 \%$ to $77.6 \%$ among PWID in nine different studies. History of previous imprisonment among non-injecting 


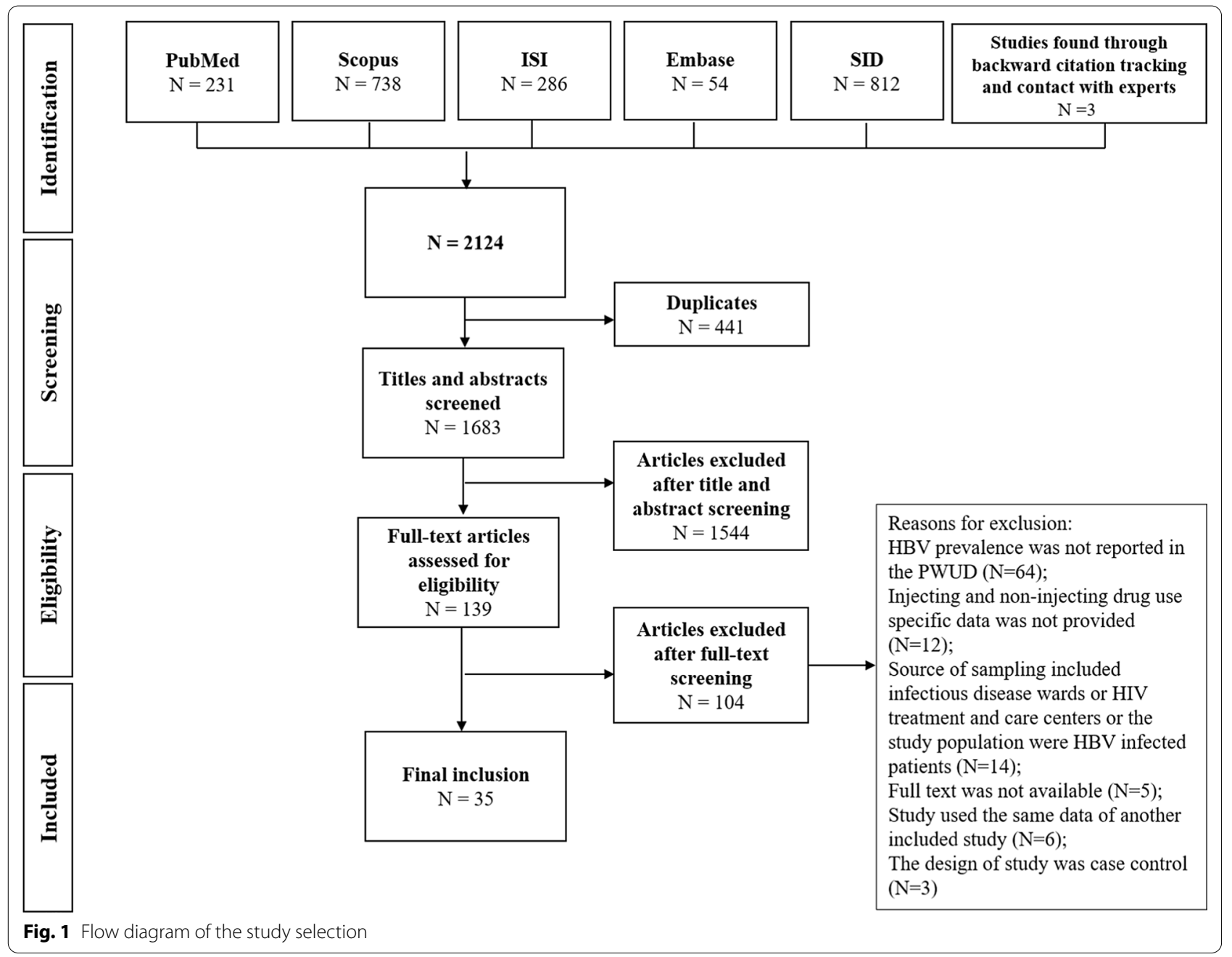

PWUD was reported in a single study and was 1.3\%. Further details on the studies' and participants' characteristics are depicted in Tables 1, 2 and 3.

\section{Quality assessment}

Critical appraisal of the included studies using an 8-item tool showed that the number of unfulfilled criteria among studies ranged from zero in three studies to 4 or more (low-quality studies) in nine studies (Table 1 ). The mean (SD) and median of the unfulfilled criteria among studies were 2.5 (1.4) and 3.0, respectively. The most prevalent items were not providing the response rate $(N=25)$, method of sampling not being random or census $(N=23)$, and not providing gender-specific data $(N=17)$.

\section{HBV prevalence among PWID and subgroups.}

The prevalence of HBsAg among PWID ranged from $0 \%$ to $24.6 \%$ in different studies (Table 2). The pooled prevalence of HBsAg positive cases among PWID was estimated to be $4.8 \%$ (95\% CI 3.7-6.2; $I^{2}=86 \%$, 33 studies, $N=9805$ ) (Fig. 2). The pooled prevalence was $5.1 \%$ (95\% CI $3.3-7.7, I^{2}=92.9 \%, 20$ studies, $\left.N=5621\right)$ in male PWID and 2.9\% (95\% CI $0.4-17.2, I^{2}=77.5 \%, 9$ studies, $N=199$ ) in female PWID.

The estimated prevalence of HBV infection in the subgroups of PWID is presented in Table 4. In a descending order, the pooled prevalence of HBsAg positive cases in different recruitment settings was estimated as following: 7.1\% (95\% CI 5.1-9.7) in treatment centres; $4.7 \%$ (95\% CI 3.4-6.4) in prisons; $4.5 \%$ (95\% CI 1.8-10.2) in community settings; $4.3 \%$ (95\% CI 1.014.6) in mixed settings, and $3.3 \%$ (95\% CI $2.3-4.6)$ in drop-in centres.

Four studies reported the co-infection of HBV, HCV, and HIV among PWID, resulting in a pooled prevalence of $2.9 \%$ (95\% CI $1.2-6.5 ; N=1362$ ). The same studies also reported HBV and $\mathrm{HCV}$ co-infection, which resulted in a pooled prevalence of 7.0\% (95\% CI 3.1-15.3). Three studies with a sample size of 1266 PWID assessed HBV and 


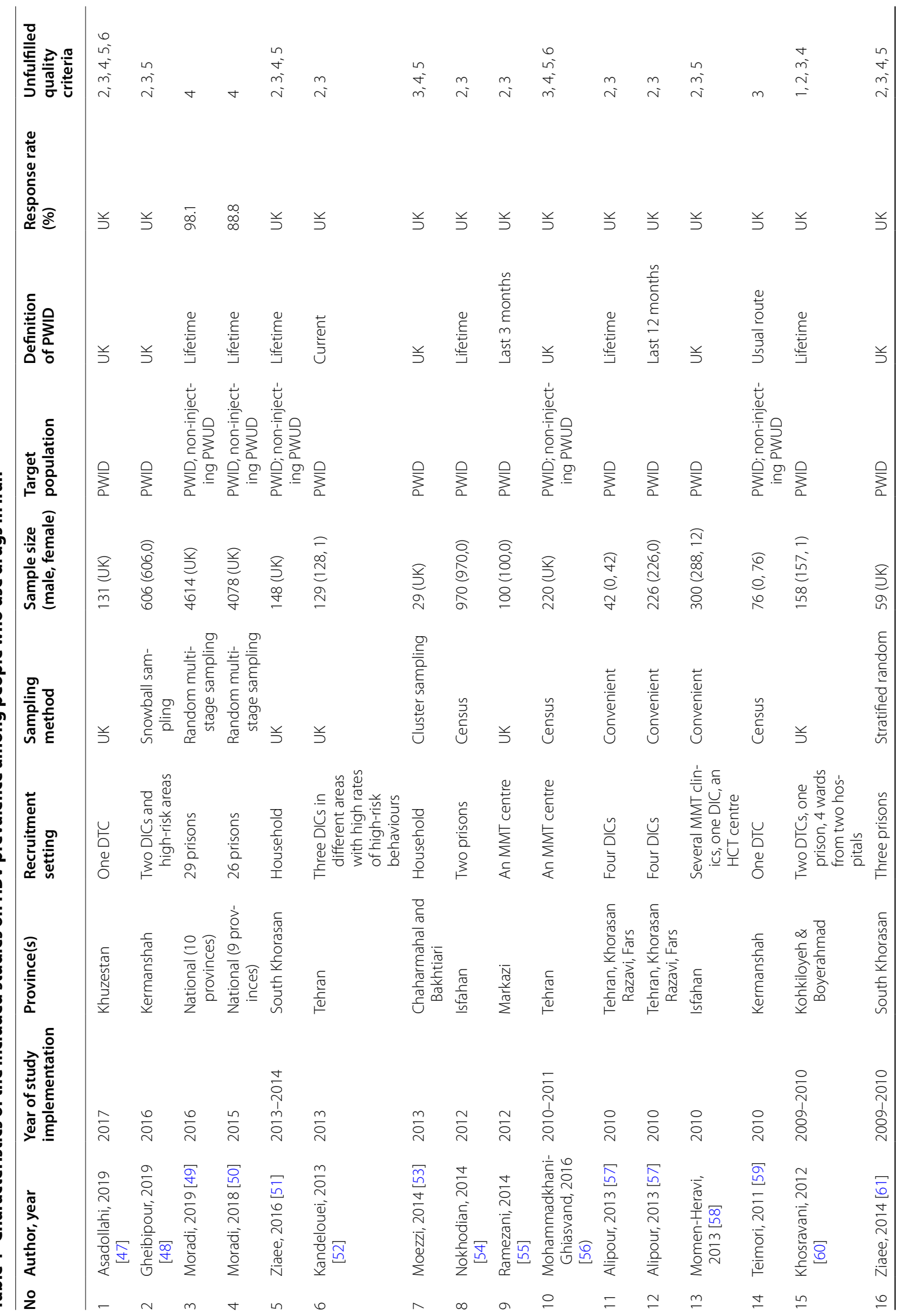




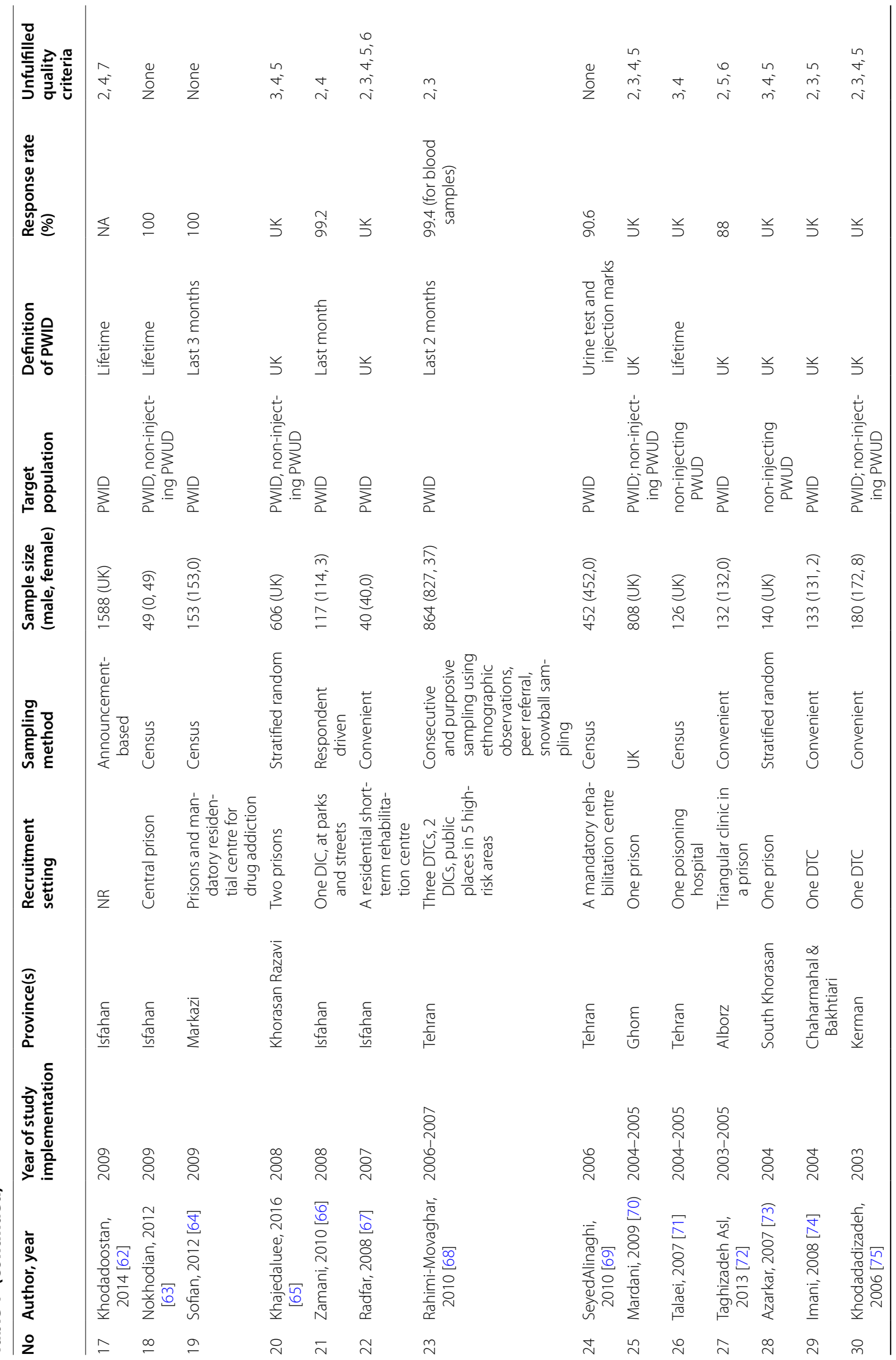




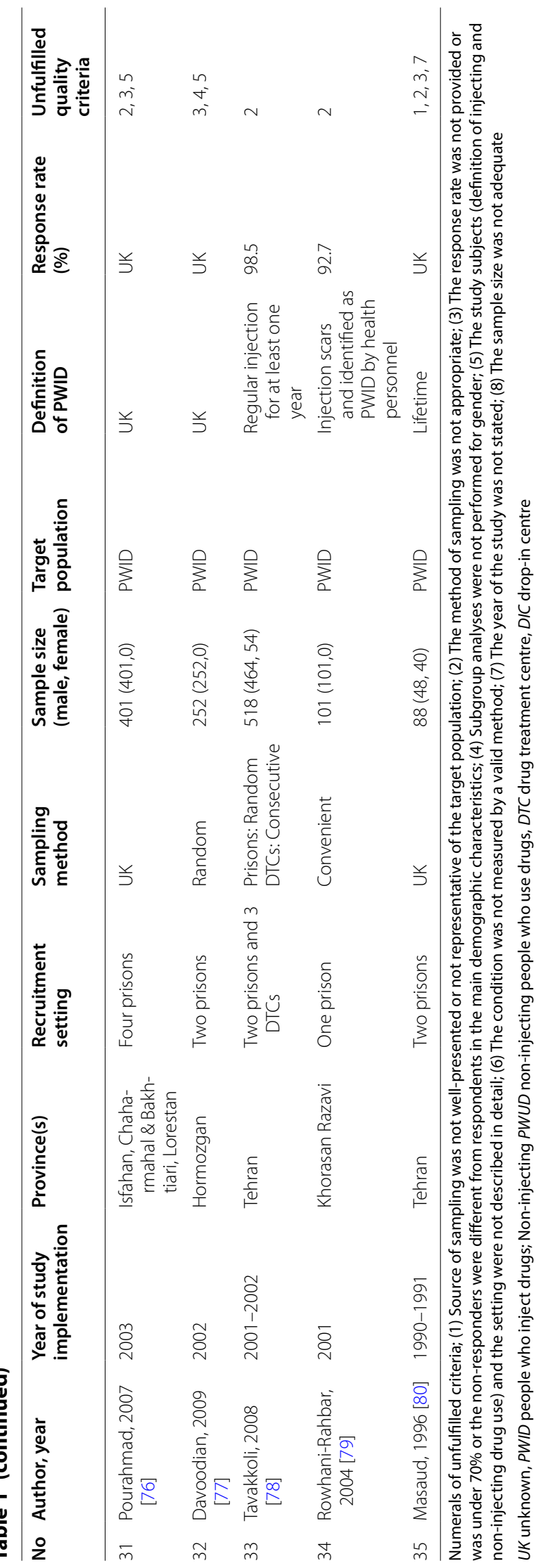




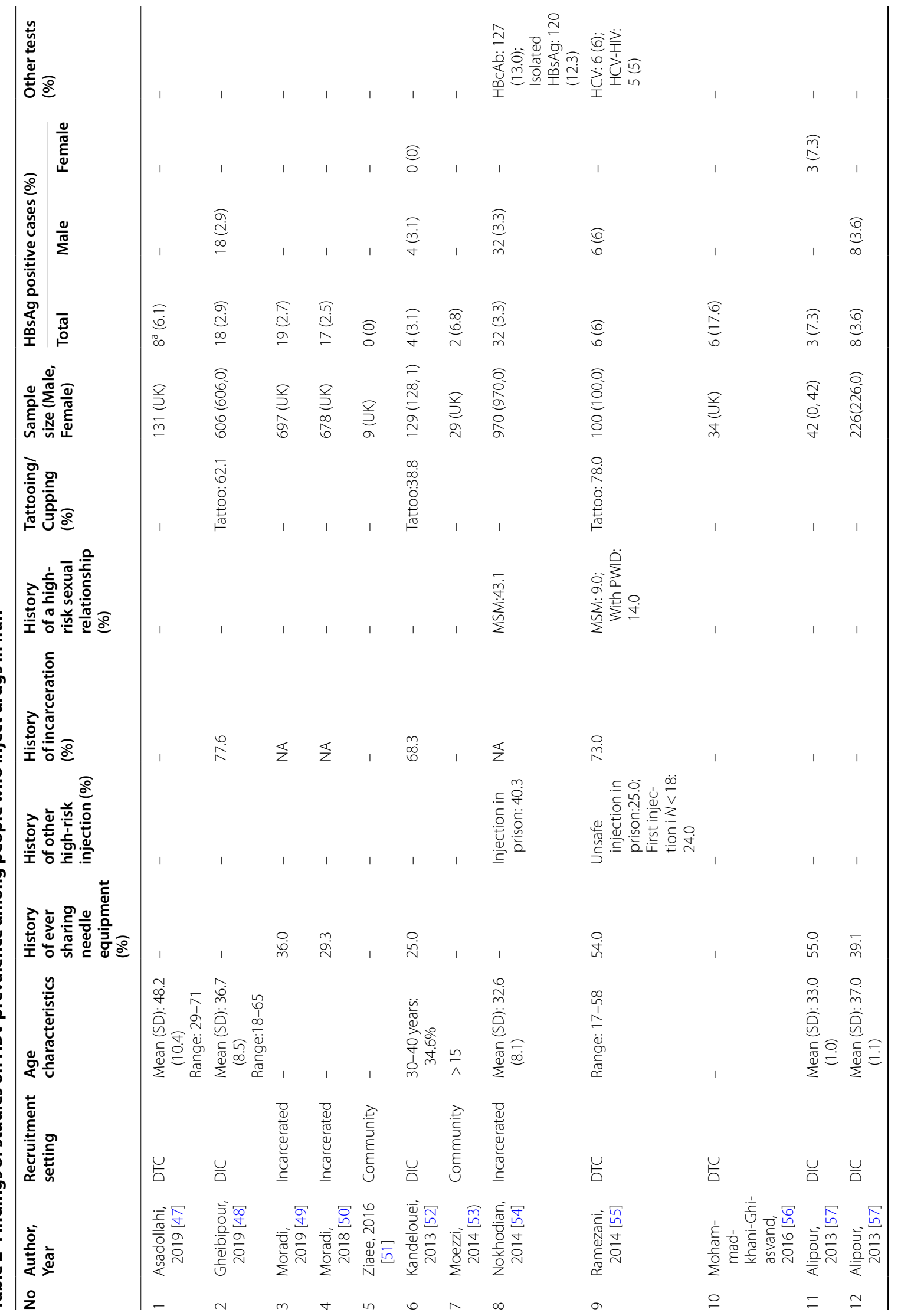




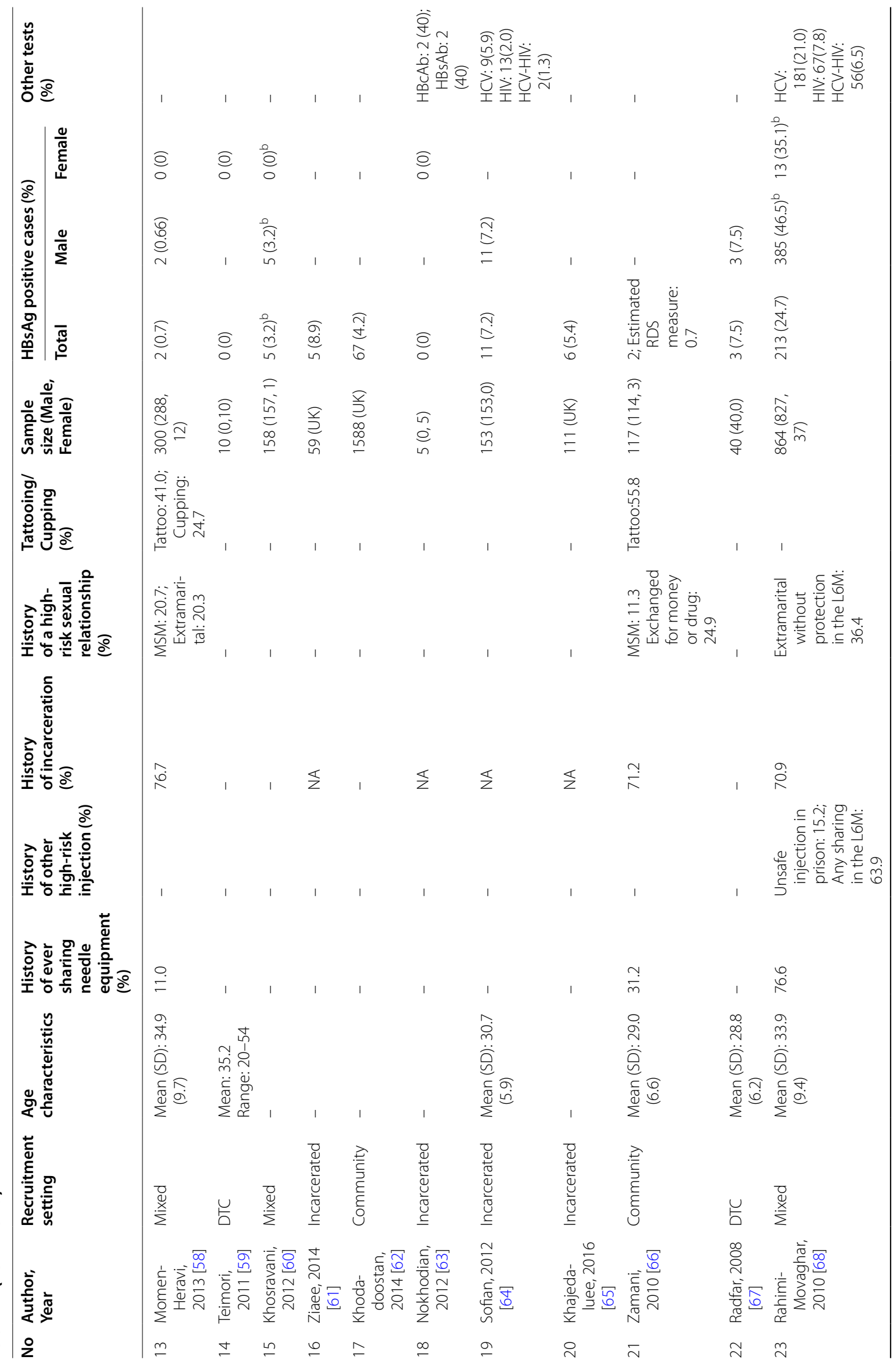




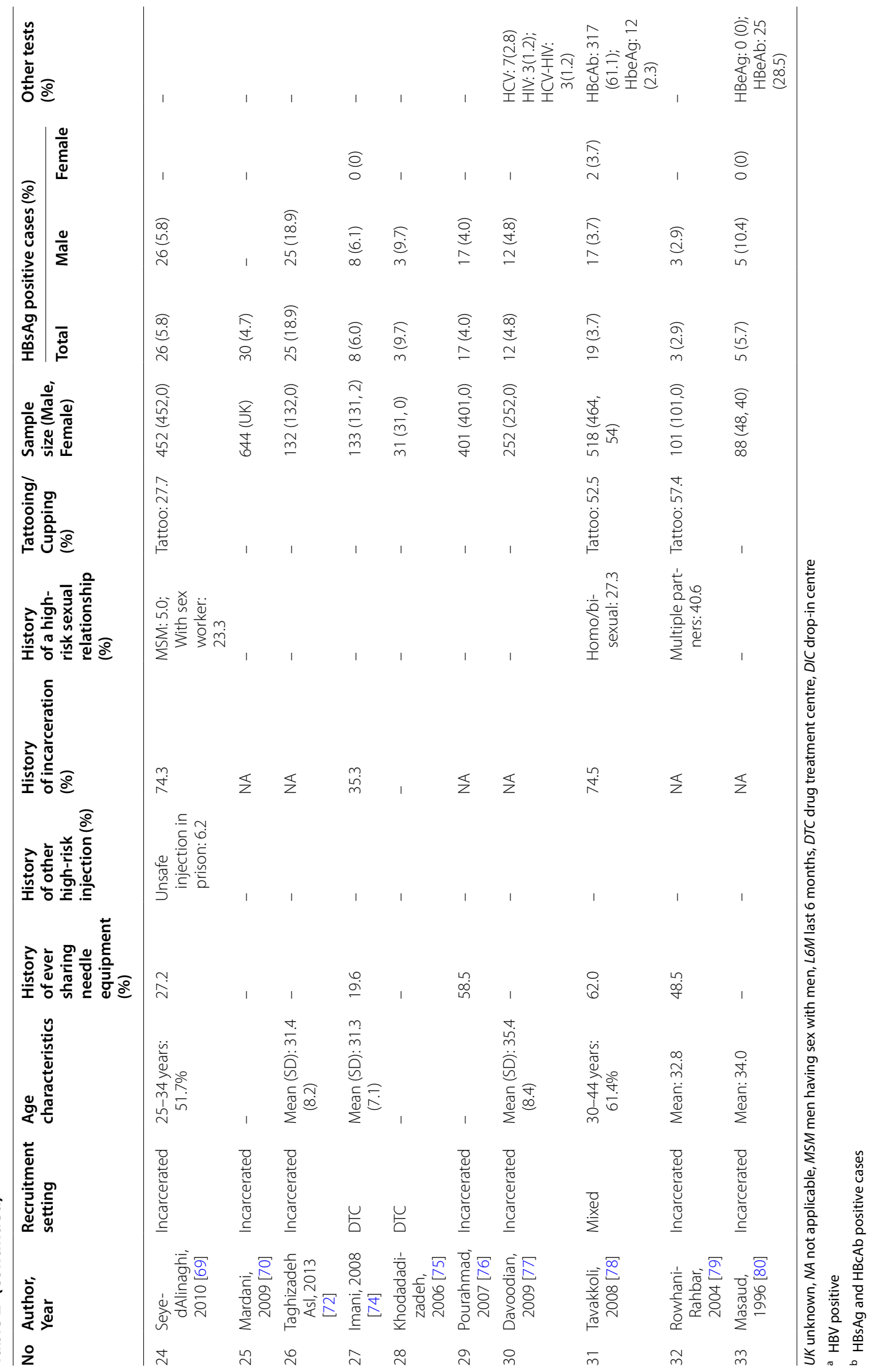




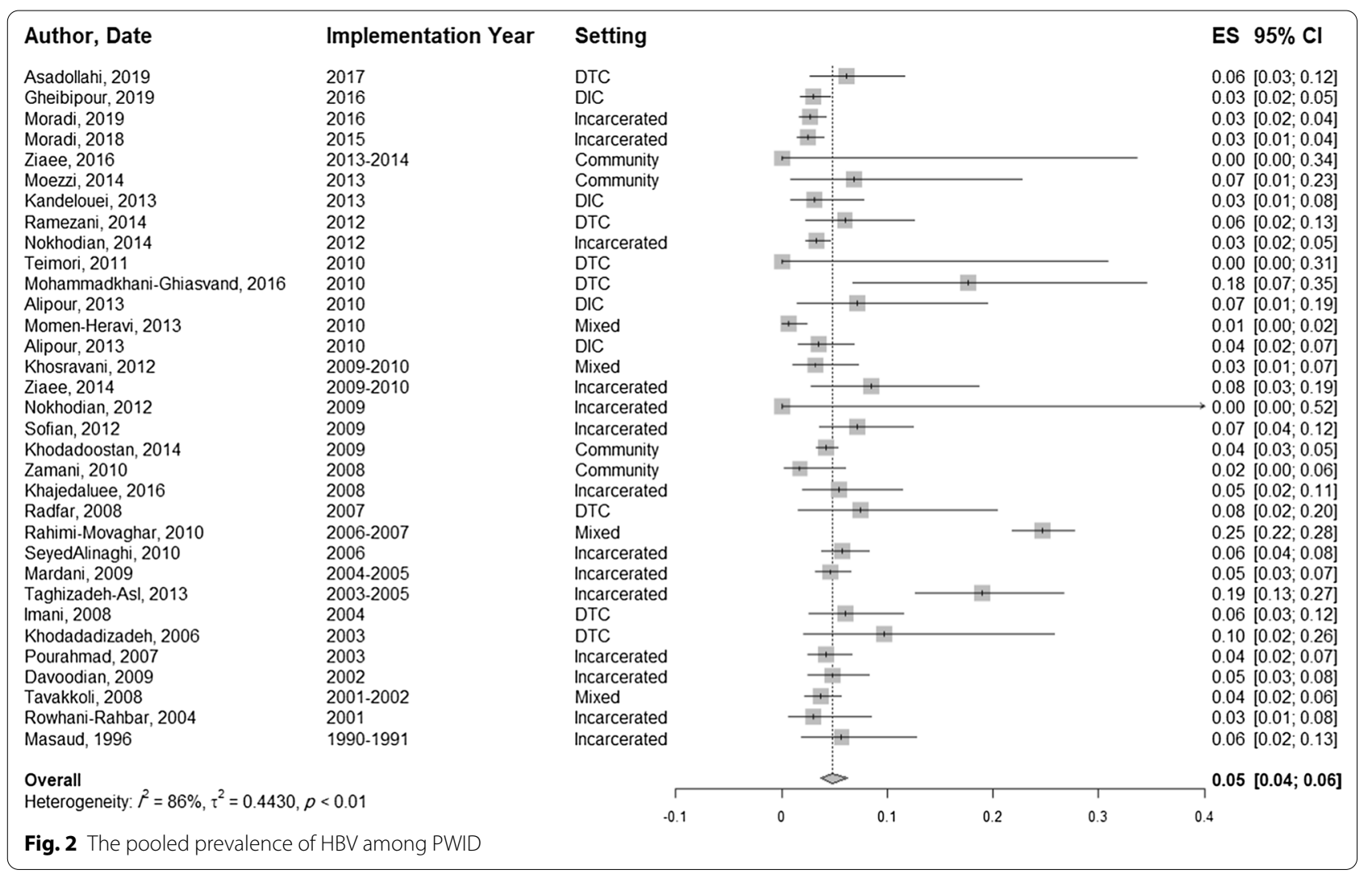

Table 3 Findings of studies on HBV prevalence among non-injecting people who use drugs in Iran $^{\mathrm{a}}$

\begin{tabular}{|c|c|c|c|c|c|c|c|c|}
\hline \multirow[t]{2}{*}{ No } & \multirow[t]{2}{*}{ Author, year } & \multirow[t]{2}{*}{ Recruitment setting } & \multirow[t]{2}{*}{ Age characteristics } & \multirow{2}{*}{$\begin{array}{l}\text { History } \\
\text { of incarceration } \\
\text { (\%) }\end{array}$} & \multirow{2}{*}{$\begin{array}{l}\text { Sample } \\
\text { size (Male, } \\
\text { Female) }\end{array}$} & \multicolumn{3}{|c|}{$\begin{array}{l}\text { HBsAg positive cases } \\
(\%)\end{array}$} \\
\hline & & & & & & Total & Male & Female \\
\hline 1 & Moradi, 2019 [49] & Incarcerated & - & NA & 3917 (UK) & $120(3.0)$ & - & - \\
\hline 2 & Moradi, 2018 [50] & Incarcerated & - & NA & $3400(U K)$ & $95(2.8)$ & - & - \\
\hline 3 & Ziaee, 2016 [51] & Community & - & - & 139 (UK) & $5(3.6)$ & - & - \\
\hline 4 & $\begin{array}{l}\text { Mohammadkhani-Ghiasvand, } 2016 \\
\text { [56] }\end{array}$ & DTC & - & - & 186 (UK) & $3(1.3)$ & - & - \\
\hline 5 & Teimori, $2011[59]$ & DTC & $\begin{array}{l}\text { Mean: } 35.2 \\
\text { Range: } 20-54\end{array}$ & 1.3 & $66(0,66)$ & $0(0)$ & - & $0(0)$ \\
\hline 6 & Nokhodian, 2012 [63] & Incarcerated & - & - & $44(0,44)$ & $0(0)$ & - & $0(0)$ \\
\hline 7 & Khajedaluee, 2016 [65] & Incarcerated & - & - & 495 (UK) & $16(3.2)$ & - & - \\
\hline 8 & Mardani, 2009 [70] & Incarcerated & - & - & 164 (UK) & $6(3.7)$ & - & - \\
\hline 9 & Talaei, 2007 [71] & Hospital & - & - & $126(U K)$ & $2(1.6)$ & - & - \\
\hline 10 & Azarkar, 2007 [73] & Incarcerated & - & - & $140(\mathrm{UK})$ & $6(4.3)$ & - & - \\
\hline 11 & Khodadadizadeh, 2006 [75] & DTC & - & - & $149(141,8)$ & $2(3.7)$ & $1(0.7)$ & $1(12.5)$ \\
\hline
\end{tabular}

NA not applicable, UK unknown, DTC drug treatment center

a No study reported data on the history of high-risk sexual relationships, tattooing, cupping and co-infection with HCV or HIV 
HIV co-infection, and the pooled estimate was $4.7 \%(95 \%$ CI 1.8-11.6).

Among different provinces, the highest prevalence of HBV in PWID was $18.9 \%$ (95\% CI 13.1-26.5, $N=132$, one study) and was reported from Alborz. Isfahan with a pooled prevalence of $2.7 \%$ (95\% CI 1.5-4.9, $N=3020,6$ studies) had the lowest prevalence. There were no separate data regarding HBV prevalence among PWID in the other 18 provinces (Fig. 3).

The pooled odds ratio of HBV infection among PWID versus non-injecting PWUD is estimated at 1.70 (95\% CI $0.90-3.21, p$ value $=0.10)$. The estimated pooled odds ratios for the association of $\mathrm{HBV}$ infection in the PWID and potential risk factors are shown in Table 5. The odds of hepatitis B in PWID with a history of imprisonment is significantly higher than those without a history of imprisonment (OR 1.72, 95\% CI 1.29-2.30, $p$ value $=0.000$ ). However, in terms of odds ratio, there were no significant association between HBV and the definition of injecting drug use, recruitment setting, gender, age, marital status, employment status, residence, lifetime history of needle sharing, lifetime history of needle sharing in prison, history of men having sex with men, history of extramarital relationships and history of tattooing in PWID participants.

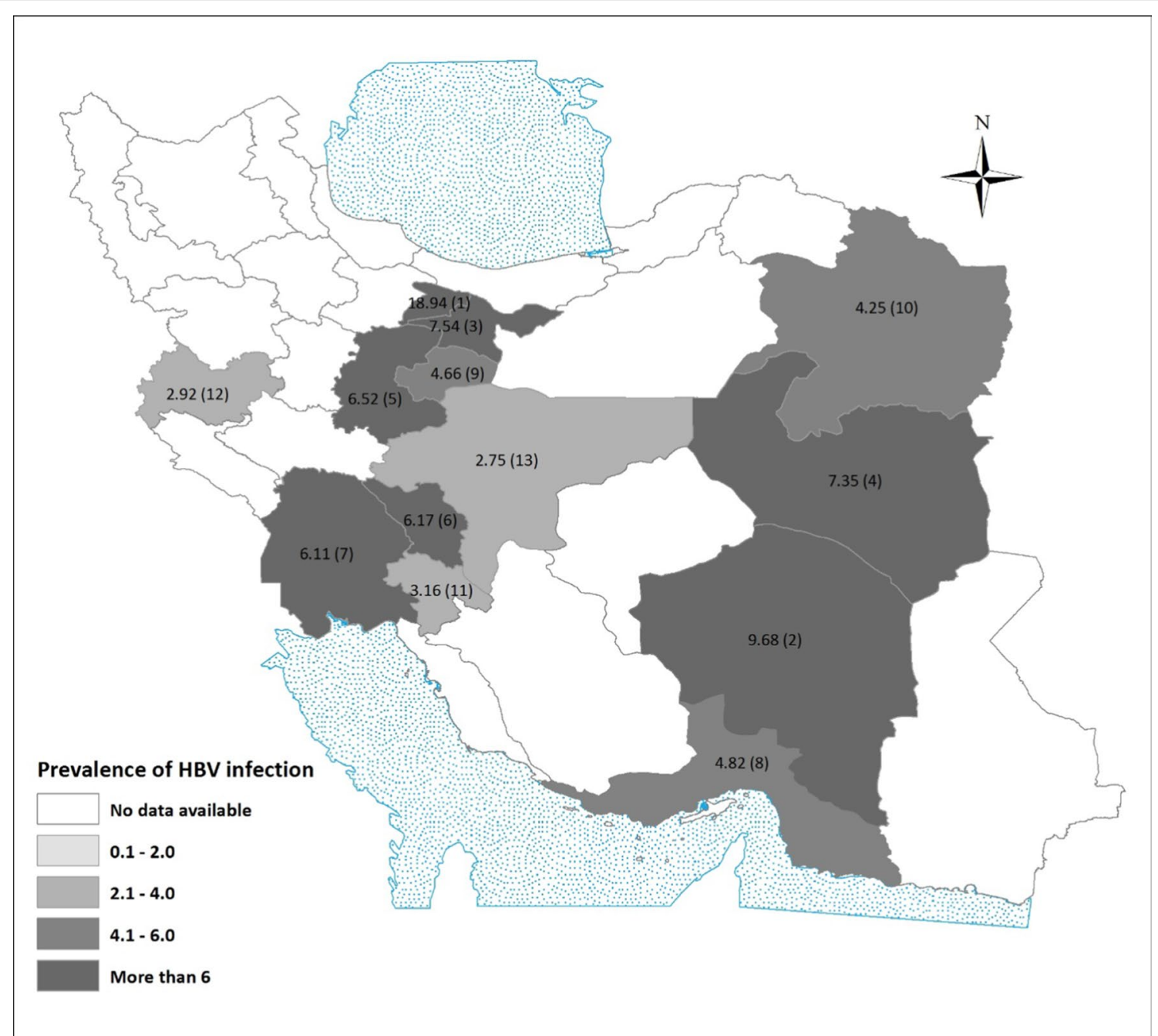

Fig. 3 The pooled prevalence of HBV among PWID in different provinces. 1: Alborz, One study, $N=132 ; 2:$ Kerman, One study, $N=31 ; 3:$ Tehran, 6 studies, $N=2085 ; 4$ : South Khorasan, 2 studies, $N=68 ; 5$ : Markazi, 2 studies, $N=253 ; 6:$ Charmahal and Bakhtiari, 2 studies, N=162; 7: Khuzestan, One study, N=131; 8: Hormozgan, One study, N=249; 9: Ghom, One study, N=644; 10: Khorasan Razavi, 2 studies, N=212; 11: Kohkiloyeh \& Boyerahmad, One study, $N=158 ; 12$ : Kermanshah, 2 studies, $N=616 ; 13$ : Isfahan, 6 studies, $N=3020$ 
Table 4 HBV pooled prevalence across subgroups of PWID

\begin{tabular}{|c|c|c|c|c|}
\hline Subgroup & PWID (N) & Studies (N) & $\begin{array}{l}\text { Pooled HBV prevalence \% (\%95 } \\
\mathrm{Cl})\end{array}$ & $I^{2}(\%)$ \\
\hline \multicolumn{5}{|l|}{ Recruitment setting } \\
\hline Treatment centre & 479 & 7 & $7.1(5.1-9.7)$ & 0 \\
\hline Prisons & 4740 & 14 & $4.7(3.4-6.4)$ & 79.0 \\
\hline Community & 1743 & 4 & $4.5(1.8-10.2)$ & 37.4 \\
\hline Mixed settings & 1840 & 4 & $4.3(1.0-14.6)$ & 96.6 \\
\hline Drop-in centres & 1003 & 4 & $3.3(2.3-4.6)$ & 0 \\
\hline \multicolumn{5}{|l|}{ Definition of PWID } \\
\hline Lifetime & 4193 & 8 & $3.4(2.7-4.1)$ & 16.6 \\
\hline Current & 2670 & 10 & $4.9(2.8-8.3)$ & 89.2 \\
\hline Unknown & 2942 & 15 & $5.7(3.9-8.3)$ & 78.6 \\
\hline \multicolumn{5}{|l|}{ Gender } \\
\hline Male & 5621 & 20 & $5.1(3.3-7.7)$ & 92.9 \\
\hline Female & 199 & 9 & $2.9(0.04-17.2)$ & 77.5 \\
\hline \multicolumn{5}{|l|}{ Age } \\
\hline Older & 864 & 3 & $5.5(4.1-7.4)$ & 9.6 \\
\hline Youth & 206 & 3 & $1.4(0.04-4.4)$ & 0 \\
\hline \multicolumn{5}{|l|}{ Marital status } \\
\hline Married $^{b}$ & 950 & 5 & $4.1(0.08-18.0)$ & 96.2 \\
\hline Never married & 1422 & 5 & $3.9(0.06-19.5)$ & 97.0 \\
\hline \multicolumn{5}{|l|}{ Employment status } \\
\hline Employed & 650 & 3 & $9.6(1.3-44.4)$ & 96.3 \\
\hline Unemployed & 619 & 3 & $6.7(0.05-49.7)$ & 89.9 \\
\hline \multicolumn{5}{|l|}{ Current residence } \\
\hline Not homeless & 969 & 2 & $14.6(1.6-63.7)$ & 98.6 \\
\hline Homeless & 492 & 2 & $12.7(1.2-63.0)$ & 95.7 \\
\hline \multicolumn{5}{|c|}{ Lifetime history of imprisonment } \\
\hline No & 610 & 6 & $1.8(0.02-12.3)$ & 91.1 \\
\hline Yes $^{c}$ & 6269 & 20 & $5.2(3.3-7.9)$ & 92.3 \\
\hline \multicolumn{5}{|c|}{ Lifetime sharing needle and syringe } \\
\hline No & 1718 & 7 & $2.9(0.08-9.3)$ & 95.1 \\
\hline Yes & 1540 & 7 & $7.0(2.4-18.3)$ & 95.1 \\
\hline \multicolumn{5}{|c|}{ Lifetime sharing needle and syringe in prison } \\
\hline No & 810 & 2 & $9.8(0.5-70.2)$ & 89.6 \\
\hline Yes & 154 & 2 & $37.2(17.1-63.1)$ & 75.6 \\
\hline \multicolumn{5}{|l|}{ EverMSM } \\
\hline No & 601 & 3 & $2.1(0.07-5.9)$ & 67.5 \\
\hline Yes & 173 & 3 & $1.1(0.01-7.3)$ & 42.5 \\
\hline \multicolumn{5}{|c|}{ Extramarital relationship } \\
\hline No & 848 & 2 & $5.5(0.01-76.0)$ & 93.8 \\
\hline Yes $^{d}$ & 316 & 2 & $10.8(0.06-68.7)$ & 88.2 \\
\hline \multicolumn{5}{|l|}{ Ever tattoo } \\
\hline No & 502 & 4 & $1.7(0.09-3.4)$ & 0 \\
\hline Yes & 624 & 4 & $2.9(1.1-7.5)$ & 66.2 \\
\hline \multicolumn{5}{|l|}{ Coinfection } \\
\hline HCV, HIV & 1362 & 4 & $2.9(1.2-6.5)$ & 73.5 \\
\hline HCV & 1362 & 4 & $7.0(3.1-15.3)$ & 89.5 \\
\hline HIV & 1266 & 3 & $4.7(1.8-11.6)$ & 88.5 \\
\hline
\end{tabular}

a Two studies defined youth under 25 years old and the other one under 30 years old

b Three studies only married, two studies married, divorced or widowed

c Including those studies recruiting samples from prisons 
Table 4 (continued)

${ }^{\mathrm{d}}$ One study defined as an extramarital relationship without protection in the last 6 months; the other defined as an ever extramarital relationship

Table 5 Pooled odds ratios for HBV infection in PWID

\begin{tabular}{|c|c|c|c|c|}
\hline Subgroup & Studies (N) & Pooled OR (\%95 Cl) & $p$ value & $I^{2}(\%)$ \\
\hline Recruitment setting & 33 & & & 79.5 \\
\hline Community & & 1 & & \\
\hline Drop-in setting & & $1.06(0.33-3.44)$ & 0.91 & \\
\hline Treatment centre & & $2.24(0.75-6.66)$ & 0.14 & \\
\hline Prison & & $1.49(0.56-3.96)$ & 0.41 & \\
\hline Mixed settings & & $1.51(0.48-4.68)$ & 0.47 & \\
\hline Definition of PWID & 33 & & & 82.3 \\
\hline Current & & 1 & & \\
\hline Lifetime & & $0.61(0.30-1.25)$ & 0.17 & \\
\hline Unknown & & $1.12(0.61-2.06)$ & 0.71 & \\
\hline Gender (male vs. female) & 7 & $1.48(0.80-2.73)$ & 0.21 & 0 \\
\hline Age (youth vs. older) & 3 & $0.46(0.14-1.54)$ & 0.21 & 0 \\
\hline Marital status (married vs. unmarried) & 5 & $1.02(0.78-1.34)$ & 0.88 & 0 \\
\hline Employment status (employed vs. unemployed) & 3 & $0.86(0.49-1.50)$ & 0.59 & 8.8 \\
\hline Residence (not homeless vs. homeless) & 2 & $0.89(0.68-1.16)$ & 0.39 & 0 \\
\hline Lifetime history of imprisonment & 6 & $1.72(1.29-2.30)$ & 0.000 & 0 \\
\hline Lifetime sharing needle and syringe & 7 & $1.57(0.82-3.01)$ & 0.17 & 57.6 \\
\hline $\mathrm{Hx}$ of sharing needle and syringe in prison & 2 & $3.98(0.32-49.24)$ & 0.28 & 80.9 \\
\hline Ever MSM & 3 & $1.52(0.12-19.94)$ & 0.75 & 46.6 \\
\hline Extramarital relationship & 2 & $0.96(0.54-1.73)$ & 0.90 & 6.6 \\
\hline Ever tattoo & 4 & $1.58(0.64-3.92)$ & 0.32 & 0 \\
\hline
\end{tabular}

MSM Men having sex with men

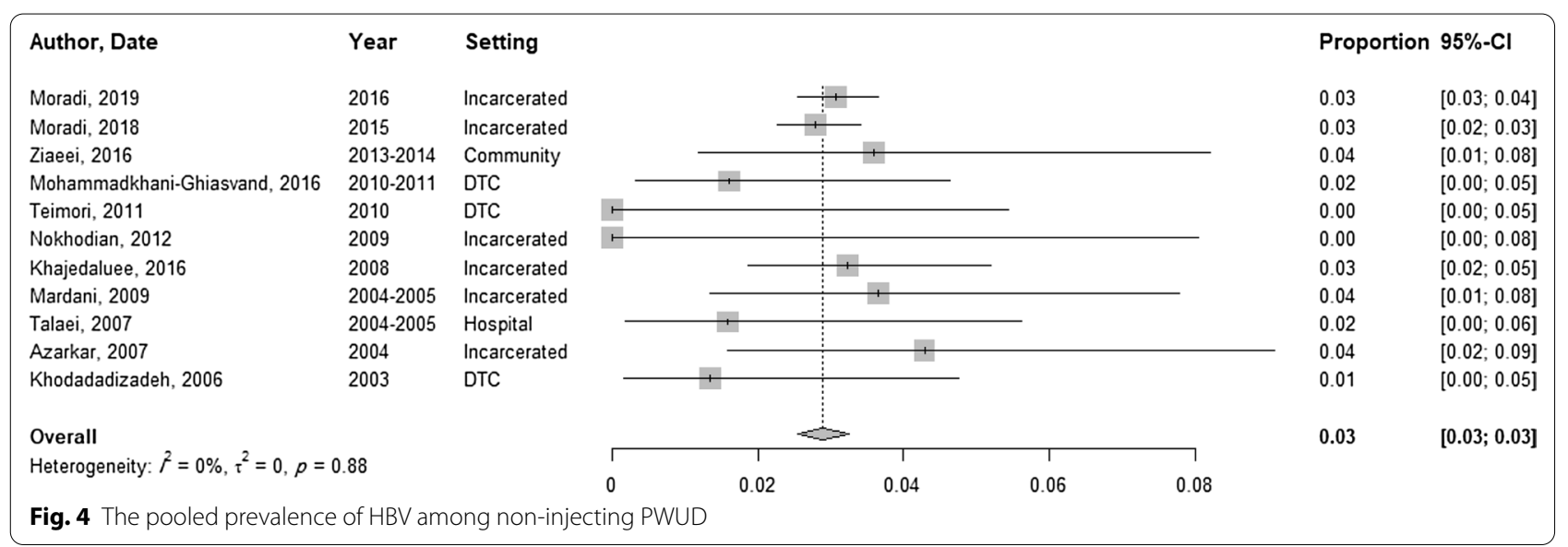

\section{HBV prevalence among non-injecting PWUD}

The total sample for non-injecting PWUD tested for HBsAg was 8826 (11 studies), and the prevalence of positive HBsAg was between 0 and 4.3\% (Table 5). The pooled prevalence in non-injecting PWUD was 2.9\% (95\% CI $\left.2.5-3.2, I^{2}=0 \%\right)$ (Fig. 4). In non-injecting
PWUD, only three studies reported prevalence by gender. Only one study reported a $0.7 \%(N=149)$ prevalence of HBsAg among male non-injecting PWUD. The pooled prevalence of $\mathrm{HBV}$ among female noninjecting PWUD was estimated to be $0.06 \%$ (95\% CI $0.0-13.7, I^{2}=42.1 \%, 3$ studies, $N=118$ ). The odds of 


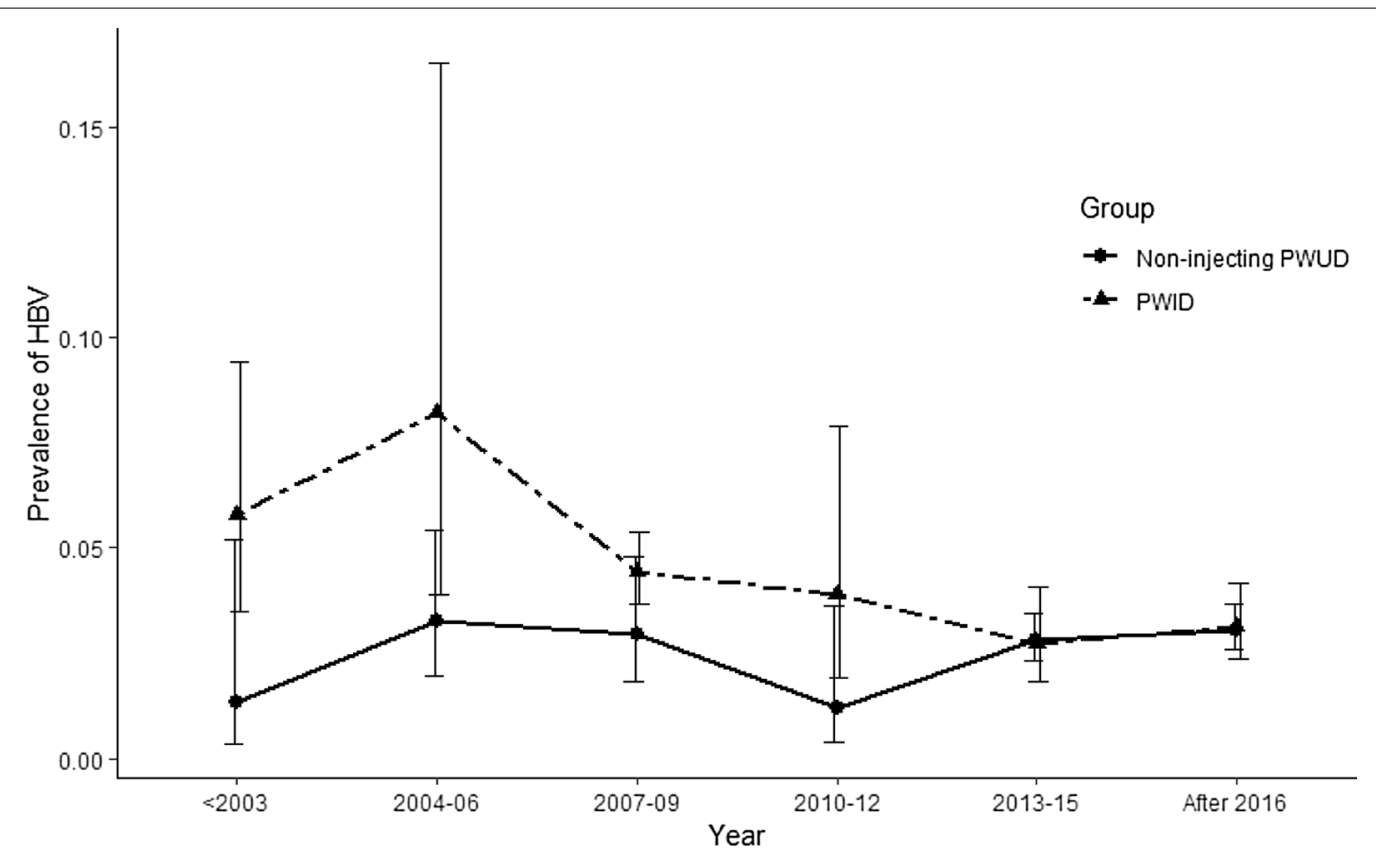

Fig. 5 Trend of HBV prevalence among PWID and non-injecting PWUD

Table 6 HBV prevalence and heterogeneity in different periods

\begin{tabular}{lllll}
\hline Year & $\begin{array}{l}\text { No. } \\
\text { of studies }\end{array}$ & $\begin{array}{l}\text { Sample size } \\
\text { (Total) }\end{array}$ & $\begin{array}{l}\text { HBV prevalence } \\
\%(\mathbf{9 5} \text { Cl) }\end{array}$ & $\boldsymbol{I}^{\mathbf{2}(\%)}$ \\
\hline PWID & & & & \\
$\leq 2003$ & 7 & 84 & $5.8(3.5-9.4)$ & 2 \\
2004-2006 & 4 & 2093 & $8.2(3.9-16.5)$ & 2 \\
2007-2009 & 8 & 2231 & $4.4(3.7-5.4)$ & 0 \\
2010-2012 & 7 & 1682 & $3.9(1.9-7.9)$ & 9 \\
2013-2015 & 4 & 845 & $2.7(1.8-4.1)$ & 0 \\
$\geq 2016$ & 3 & 1434 & $3.1(2.3-4.1)$ & 0 \\
Non-injecting PWUD & & & \\
$\leq 2003$ & 1 & 149 & $1.3(0.3-5.2)$ & - \\
2004-2006 & 3 & 430 & $3.3(1.9-5.4)$ & 0 \\
2007-2009 & 2 & 539 & $3.0(1.8-4.8)$ & 0 \\
2010-2012 & 2 & 252 & $1.2(0.4-3.6)$ & 0 \\
2013-2015 & 2 & 3539 & $2.8(2.3-3.4)$ & 0 \\
$\geq 2016$ & 1 & 3917 & $3.0(2.6-3.6)$ & - \\
\hline Modet Rand & & & &
\end{tabular}

Model: Random Effects Model

HBV infection were not significantly associated with the recruitment setting.

\section{Time trend analysis}

The trends of HBV prevalence among PWID and noninjecting PWUD over time are presented in Fig. 5 and Table 6. HBV pooled prevalence among PWID seems to has increased from 5.8\% (95\% CI 3.5-9.4) in 2003 and before, to $8.2 \%$ (95\% CI 3.9-16.5) in 2004-2006; however, this increase was not significant $(b=-0.06 ; p$ value $=0.30$ ). Afterwards, the pooled HBV prevalence has dropped significantly to $3.1 \%$ (95\% CI $2.3-4.1)$ in 2016 and later $(b=-0.07 ; p$ value $=0.05)$. The pooled prevalence of HBV among non-injecting PWUD seems to have increased from 2003 and before until 2004-2006 and then decreased until 2012 and increased afterwards; nonetheless, none of these trends among non-injecting PWUD was statistically significant $(p$ value $=0.23,0.17$, 0.12 , respectively).

\section{Heterogeneity of the studies}

For finding the source of heterogeneity between the studies on PWID, meta-regression analyses were performed and none of the following potential predictors had significant influence on HBV prevalence: number of unfulfilled quality criteria ( $p$ value $=0.3$ ), the definition of injection drug use as lifetime or unknown versus current $(p$ value $=0.2$ ), and setting for recruiting the sample (all versus community; $p$ value $=0.5$ ). The results of meta-regression on studies on non-injecting PWUD assessing potential predictors were also not significant: the number of unfulfilled quality criteria ( $p$ value $=0.9$ ), the definition of non-injection as lifetime or unknown versus current $(p$ value $=0.9$ ), and setting for recruiting the sample (all versus community; $p$ value $=0.2$ ). 


\section{Discussion}

We found a pooled prevalence of $4.8 \%$ for HBV among PWID in Iran; $5.1 \%$ in male and $2.9 \%$ in female subgroups. One previous systematic review on Iranian high-risk population groups, including other vulnerable groups such as sex workers and prisoners, also estimated a prevalence of $4.8 \% \mathrm{HBV}$ infection [22]. In a systematic review published by Degenhardt et al. in 2017, the prevalence of HBV among PWID was investigated. Globally, it has been estimated that $9 \%$ of PWID are positive for HBsAg and the estimate for the Middle East and North African region is $8.1 \%$ [4]. This paper reviewed studies published from 2011 to June 2017 and included six studies from Iran, three of which recruited the participants from infectious wards or HIV care clinics. The review reported a pooled HBV prevalence of 3.9\% (95\% CI 2.94.9) among Iranian PWID.

In our study, the odds of HBV were significantly higher among PWID with a history of imprisonment. Our results are in concordance with the previous literature [3, 23-26]. In intermediate-prevalence areas for $\mathrm{HBV}$, including Iran, the predominant mode of HBV transmission is through sexual contact and injecting drug use $[27,28]$. Our study showed a higher prevalence of HBV among PWID with a history of sharing needles and syringes and high-risk sexual behaviours (such as extramarital relationship or MSM). However, we found no significant association between these factors and HBV infection in terms of odds ratio, which may be due to small sample sizes and power.

The pooled prevalence of $\mathrm{HBV}$ among Iranian noninjecting PWUD was $2.9 \%$. Due to lack of data, the associated risk factors could not be further investigated. Two recent systematic reviews estimated the prevalence of HBV infection among the Iranian general population to be 2.2 and $3.0 \%[29,30]$; seemingly not lower than the prevalence in non-injecting PWUD in our study. Presumably, high-risk sexual behaviours among non-injecting PWUD are similar to the general population in Iran.

We performed a trend analysis of $\mathrm{HBV}$ prevalence based on the implementation year. Although the prevalence of HBV among PWID increased slightly before 2006, this increase was not found significant. Since then, HBV prevalence among PWID has decreased significantly and reached $3.1 \%$ in recent years, which is not considerably higher than the general population. Similarly, the HBV prevalence declined since 2006 in the Iranian general population [29]. However, none of the trends seen for HBV prevalence among non-injecting PWUD was statistically significant.

The recent significant reduction in the prevalence of HBV among PWID may be attributed to public health measures implemented against HIV and hepatitis. Harm reduction measures were initiated in 2002 and scaled up in 2005 and included needle and syringe programs and opioid substitution treatment [31-34]. Needle and syringe and opioid substitution treatment programs continued to grow nationally in the following decade $[35,36]$; hypothetically, being the cause for the current reduction in HBV prevalence among PWID. A similar trend has been reported for HIV infection among PWID [15]. It seems that these changes are the results of the decrease in high-risk behaviours. In a national study in 2010, $36.9 \%$ reported a positive history of unsafe injection in the previous month [37]. In the latest national survey on drug users in 2018, only $22 \%$ of the PWID reported lending or/borrowing used syringes in the previous year [12]. HBV vaccination coverage was initiated in 1992 targeting newborns; however, there has been no vaccination program specifically for high-risk groups including PWUD. Another review from Iran has shown that the weighted mean age of first injection is 25.8 [38]. As a result, this policy measure may have partly targeted the current generation of PWID and a higher impact would be expected in the future.

For maintaining the reduction in HBV prevalence in the PWID, it seems that sustaining needle syringe and opioid substitution treatment programs are vital. History of imprisonment was found as a correlate of HBV infection among PWID, which necessitates a further expansion of harm reduction measures such as needle and syringe programs and HBV diagnostic and treatment programs in the prisons' health system $[39,40]$. Targeted HBV vaccination for PWID, whether with the regular or accelerated protocol is a recommended intervention for $\mathrm{HBV}$ control $[41,42]$. Viral hepatitis, including HBV, results in higher mortality than HIV [43]; however, globally it has been neglected in the majority of the policies [3]. The WHO's package for ending viral hepatitis includes a high coverage of needle syringe program, opioid substitution treatments and treatment for other drug types, diagnosis and treatment of viral hepatitis for PWUD [1]. In spite of expansion in harm reduction services in Iran, the coverage is still low to moderate [44].

Though the pooled prevalence was higher among the male subgroup of PWID compared with female subgroup, the difference was not statistically significant. Most of the studies on non-injecting PWUD did not report gender-specific data; thus, it could not be further interpreted. Furthermore, female-specific risk factors for HBV infection were not investigated in the included studies. Globally, HBV prevalence among female and male PWID subgroups was not also significantly different [45].

We faced notable shortcomings in a number of included studies. There were $9(25.7 \%)$ low-quality 
studies among total inclusions. Almost $45 \%$ of the studies did not report the definition of injecting drug use, and in the others, a variety of definitions were used. Although sexual transmission is the major route of HBV acquisition, only a few studies evaluated the history of high-risk behaviours using various definitions.

There were fewer studies targeting non-injecting PWUD. Further data regarding possible risk factors, such as high-risk sexual contacts, among non-injecting PWUD, were not collected. HBV prevalence among PWUD has not been investigated in several provinces. For instance, there is no study on PWUD in Golestan province, in which there is evidence of a high HBV prevalence among the general population [30]. Rural areas were also completely neglected. Moreover, the association between HBV infection and type of substances has not been investigated. With an increase in methamphetamine use in the country [46], the HBV epidemics among PWUD might be affected. Therefore, there is a need for additional high-quality researches for providing a more accurate picture of $\mathrm{HBV}$ prevalence among PWUD subgroups.

We were able to provide pooled HBV prevalence among both injecting and non-injecting PWUD and several subgroups in Iran. However, we faced considerable heterogeneity among PWID. Thus, through subgroup analyses and meta-regression model, we tried to investigate the source of heterogeneity. Yet, the heterogeneity was still considerable among most of the subgroups and we did not identify any source in the meta-regression model. Therefore, the results should be interpreted with caution.

\section{Conclusion}

The prevalence of HBV infection among non-injecting PWUD and even PWID was not considerably higher than the Iranian general population. Although PWID, as well as non-injecting PWUD, are considered as the main high-risk groups for HIV and HCV infections in Iran, it is not the case for HBV infection. A significant decreasing trend was detected for HBV infection among PWID subgroup in recent years. Still, it seems that there are subgroups of PWID, which have not adequately benefited from harm reduction interventions as well as specific preventive measures for HBV. Future programs should more specifically target these high-risk groups.

\footnotetext{
Abbreviations

Cl: Confidence interval; DIC: Drop-in centre; DTC: Drug treatment centre; HBsAg: Hepatitis B Virus surface antigen; HBV: Hepatitis B Virus; HCV: Hepatitis C virus; HIV: Human immunodeficiency virus; L6M: Last 6 months; MSM: Men having sex with men; NA: Not applicable; PRISMA: Preferred Reporting Items for Systematic Reviews and Meta-analysis; PWID: People who inject
}

drugs; PWUD: People who use drugs; UK: Unknown; WHO: World Health Organization.

\section{Acknowledgements}

The authors would like to thank Mr Shahab Baheshmat for his contribution to the statistical analysis and Ms Jamileh Rahimi for her contribution to the data extraction.

\section{Authors' contributions \\ ARM conceived the idea for the review. HR, BS, MAE, ARM, and YRA did all the searches, screening, review, data extraction, and quality assessment. Data analysis was planned and done by JG and YRA. YRA, JG, and ARM wrote the first draft of the manuscript. All authors made substantial contributions to the critical review, editing, and revision of the manuscript. All authors read and approved the final manuscript.}

\section{Funding}

This study was supported financially by the Iranian National Institute for Medical Research Development (NIMAD) [Grant No. 940043]. The funding source had no role in the study design, implementation, analysis and interpretation of the data, and in the writing of the manuscript.

\section{Availability of data and materials}

All data generated or analysed during this study are included in this published article.

Ethics approval and consent to participate

Not applicable.

\section{Consent for publication}

Not applicable.

\section{Competing interests}

The authors declare that they have no competing interests.

\section{Author details}

${ }^{1}$ Iranian National Center for Addiction Studies (INCAS), Tehran University of Medical Sciences, No. 486, South Karegar Ave., 1336616357 Tehran, Iran. ${ }^{2}$ Department of Epidemiology, School of Public Health and Safety, Shahid Beheshti University of Medical Sciences, Tehran, Iran. ${ }^{3}$ Mental Health Department, Johns Hopkins Bloomberg School of Public Health, Baltimore, USA.

Received: 4 March 2020 Accepted: 8 October 2020

Published online: 21 October 2020

\section{References}

1. WHO. Global Health Sector Strategy on Viral Hepatitis 2016-2021; Toward Ending Viral Hepatitis. Geneva, Switzerland: World Health Organization; 2016

2. IHME Hepatitis Facts. Institute for Health Metrics and Evaluation. https:// hepatitis.ihme.services. Accessed 31 January 2020.

3. Degenhardt L, Charlson F, Stanaway J, Larney S, Alexander LT, Hickman $M$, et al. Estimating the burden of disease attributable to injecting drug use as a risk factor for HIV, hepatitis C, and hepatitis B: findings from the Global Burden of Disease Study 2013. Lancet Infect Dis. 2016;16(12):1385-98.

4. Degenhardt L, Peacock A, Colledge S, Leung J, Grebely J, Vickerman P, et al. Global prevalence of injecting drug use and sociodemographic characteristics and prevalence of HIV, HBV , and HCV in people who inject drugs: a multistage systematic review. Lancet Global Health. 2017;5(12):e1192-207.

5. Vahdani P, Hosseini-Moghaddam SM, Family A, Moheb-Dezfouli R. Prevalence of HBV, HCV, HIV and syphilis among homeless subjects older than fifteen years in Tehran. Arch Iran Med. 2009;12(5):483-7.

6. Noska AJ, Belperio PS, Loomis TP, O'Toole TP, Backus LI. Prevalence of Human Immunodeficiency Virus, Hepatitis C Virus, and Hepatitis B Virus Among Homeless and Nonhomeless United States Veterans. Clin Infect Dis. 2017;65(2):252-8. 
7. Kamarulzaman A, Reid SE, Schwitters A, Wiessing L, El-Bassel N, Dolan K, et al. Prevention of transmission of HIV, hepatitis B virus, hepatitis $C$ virus, and tuberculosis in prisoners. The Lancet. 2016;388(10049):1115-26.

8. Danaei G, Farzadfar F, Kelishadi R, Rashidian A, Rouhani OM, Ahmadnia S, et al. Iran in transition. Lancet. 2019;393(10184):1984-2005.

9. Sharifi V, Amin-Esmaeili M, Hajebi A, Motevalian A, Radgoodarzi R, Hefazi M, et al. Twelve-month prevalence and correlates of psychiatric disorders in Iran: the Iranian Mental Health Survey, 2011. Arch Iran Med. 2015:18(2):76-84

10. Narenjiha H, Rafiei H, Baghestani AR, Nouri R, Ghafouri B, Soleimaninia L. Rapid situation assessment of drug abuse in Iran, Year 2007 (in Persian). Tehran: Danjeh Publication; 2009.

11. Akbari H, Roshanpajouh M, Nourijelyani K, Mansournia M-A, RahimiMovaghar A, Yazdani K. Profile of drug users in the residential treatment centers of Tehran. Iran Health Promot Perspect. 2019;9(3):248-54.

12. Rafiei $\mathrm{H}$, Madani $\mathrm{S}$, Narenjiha $\mathrm{H}$, Alipour F. Final report of rapid situation assessment of drug abuse in Iran, 2018 (in Persian) 2019.

13. Rahimi-Movaghar A, Amin-Esmaeili M, Haghdoost AA, Sadeghirad B, Mohraz M. HIV prevalence amongst injecting drug users in Iran: a systematic review of studies conducted during the decade 1998-2007. Int J Drug Policy. 2012;23(4):271-8.

14. Malekinejad M, Navadeh S, Lotfizadeh A, Rahimi-Movaghar A, AminEsmaeili M, Noroozi A. High hepatitis C virus prevalence among drug users in Iran: systematic review and meta-analysis of epidemiological evidence. Int J Inf Dis. 2015;40:116-30.

15. Rahimi J, Gholami J, Amin-Esmaeili M, Fotouhi A, Rafiemanesh H, Shadloo $B$, et al. HIV prevalence among people who inject drugs (PWID) and related factors in Iran: a systematic review, meta-analysis and trend analysis. In print; Addiction

16. Behzadifar M, Gorji HA, Rezapour A, Bragazzi NL. Prevalence of hepatitis $C$ virus infection among prisoners in Iran: a systematic review and metaanalysis. Harm Reduct J. 2018;15(1):24.

17. Amin-Esmaeili M, Rahimi-Movaghar A, Haghdoost AA, Mohraz M. Evidence of HIV epidemics among non-injecting drug users in Iran: a systematic review. Addiction. 2012;107(11):1929-38.

18. Centers for Disease Control and Prevention. Interpretation of Hepatitis B Serologic Test Results. Department of Health and Human Services.

19. Munn Z, Moola S, Riitano D, Lisy K. The development of a critical appraisal tool for use in systematic reviews addressing questions of prevalence. Int J Health Policy Manag. 2014;3(3):123-8.

20. Rostam-Abadi Y, Gholami J, Amin-Esmaeili M, Safarcherati A, Mojtabai R, Ghadirzadeh MR, et al. Tramadol use and public health consequences in Iran: a systematic review and meta-analysis. Addiction. 2020;n/a(n/a).

21. Higgins J, Thomas J, Chandler J, Cumpston M, Li T, Page M, et al. Cochrane Handbook for Systematic Reviews of Interventions version 6.1 (updated September 2020). Cochrane, Available from wwwtrainingcochraneorg/ handbook. 2020.

22. Almasi-Hashiani A, Ayubi E, Mansori K, Salehi-Vaziri M, Moradi Y, Gholamaliei B, et al. Prevalence of hepatitis B virus infection among Iranian high risk groups: a systematic review and meta-analysis. Gastroenterol Hepatol Bed Bench. 2018;11(2):91-100.

23. Wirtz AL, Yeh PT, Flath NL, Beyrer C, Dolan K. HIV and viral hepatitis among imprisoned key populations. Epidemiol Rev. 2018:40(1):12-26.

24. Dana D, Zary N, Peyman A, Behrooz A. Risk prison and hepatitis B virus infection among inmates with history of drug injection in Isfahan, Iran. Sci World J. 2013;2013:735761.

25. Dolan K, Wirtz AL, Moazen B, Ndeffo-Mbah M, Galvani A, Kinner SA, et al. Global burden of HIV, viral hepatitis, and tuberculosis in prisoners and detainees. Lancet. 2016;388(10049):1089-102.

26. Falla AM, Hofstraat SHI, Duffell E, Hahné SJM, Tavoschi L, Veldhuiizen IK. Hepatitis B/C in the countries of the EU/EEA: a systematic review of the prevalence among at-risk groups. BMC Infect Dis. 2018;18(1):79.

27. Ott JJ, Stevens GA, Groeger J, Wiersma ST. Global epidemiology of hepatitis B virus infection: New estimates of age-specific HBsAg seroprevalence and endemicity. Vaccine. 2012;30(12):2212-9.

28. Schweitzer A, Horn J, Mikolajczyk RT, Krause G, Ott JJ. Estimations of worldwide prevalence of chronic hepatitis B virus infection: a systematic review of data published between 1965 and 2013. Lancet. 2015;386(10003):1546-55.

29. Salehi-Vaziri M, Sadeghi F, Almasi Hashiani A, Gholami Fesharaki M, Alavian SM. Hepatitis B virus infection in the general population of
Iran: an updated systematic review and meta-analysis. Hepatitis Mon. 2016;16(4):e35577.

30. Mohammadi Z, Keshtkar A, Eghtesad S, Jeddian A, Pourfatholah AA Maghsudlu M, et al. Epidemiological profile of hepatitis B virus infection in Iran in the past 25 years; a systematic review and meta-analysis of general population studies. Middle East J Dig Dis. 2016;8(1):5-18.

31. Amin-Esmaeili M, Rahimi-Movaghar A, Razaghi EM, Baghestani AR, Jafari $S$. Factors correlated with hepatitis $C$ and $B$ virus infections among injecting drug users in Tehran, IR Iran. Hepat Mon. 2012;12(1):23-31.

32. Office for Mental and social Health and Substance Abuse. National report on drug treatment and harm reduction services (In Persian). Tehran, Iran: Iran Ministry of Health; 2008.

33. Ekhtiari H, Noroozi A, Farhoudian A, Radfar SR, Hajebi A, Sefatian S, et al. The evolution of addiction treatment and harm reduction programs in Iran: a chaotic response or a synergistic diversity? Addiction. In print.

34. Amin-Esmaeili M, Rahimi-Movaghar A, Gholamrezaei M, Razaghi E. Profile of people who inject drugs in Tehran, Iran. Acta Medica Iran. 2016:54:793-805.

35. Center for Disease Management. Islamic Republic of Iran AIDS progress report on monitoring of the United Nations General Assembly Special Session on HIV and AIDS. Tehran, Iran: Iran Ministry of Health; 2012.

36. Haghdoost A., Osouli M., Sadjadi L., Mirzazadeh A., Navadeh S., A. M. HIV Bio-Behavioral Surveillance of Injecting Drug Users 2010: Project Report [In Persian]. Center for Communicable Disease Management, Regional Knowledge Hub for HIV/AIDS Surveillance at Kerman University of Medical Sciences; 2012.

37. Khajehkazemi R, Osooli M, Sajadi L, Karamouzian M, Sedaghat A, Fahimfar $\mathrm{N}$, et al. HIV prevalence and risk behaviours among people who inject drugs in Iran: the 2010 National Surveillance Survey. Sex Trans Inf. 2013;89(3):iii29-32.

38. Rahimi-Movaghar A, Amin-Esmaeili M, Shadloo B, Noroozi A, Malekinejad M. Transition to injecting drug use in Iran: A systematic review of qualitative and quantitative evidence. Int J Drug Policy. 2015;26(9):808-19.

39. Kandelouei T, Vaezjalali M. Investigation of relative risk factors of hepatitis $B$ virus core antibody positivity among intravenous drug users in Tehran 2013. Novelty Biomed. 2017:5:2.

40. Alavian SM. Accelerated vaccination against HBV infection is an important strategy for the control of HBV infection in prisons. Rev Soc Brasil Med Trop. 2011;44(5):652.

41. WHO. Guidance on Prevention of Viral Hepatitis B and C Among People Who Inject Drugs Geneva, Switzerland: WHO Document Production Services: 2012.

42. Walsh N, Verster A, Rodolph M, Akl EA. WHO guidance on the prevention of viral hepatitis B and C among people who inject drugs. Int J Drug Policy. 2014:25(3):363-71.

43. Degenhardt L, Grebely J, Stone J, Hickman M, Vickerman P, Marshall BDL, et al. Global patterns of opioid use and dependence: harms to populations, interventions, and future action. Lancet. 2019;394(10208):1560-79.

44. Rahimi-Movaghar A, Amin-Esmaeili M, Shadloo B, Aaraj E. Assessment of situation and response of drug use and its harm in the Middle East and North Africa, 2017. Lebanon: Middle East and North Africa Harm Reduction Association (MENAHRA) and Iranian National Center for Addiction Studies (INCAS); 2018

45. Leung J, Peacock A, Colledge S, Grebely J, Cunningham EB, Hickman $M$, et al. A global meta-analysis of the prevalence of HIV, hepatitis $C$ virus, and hepatitis $B$ virus among people who inject drugs-do gender-based differences vary by country-level indicators? J Infect Dis. 2019;220(1):78-90.

46. Shadloo B, Amin-Esmaeili M, Haft-Baradaran M, Noroozi A, GhorbanJahromi R, Rahimi-Movaghar A. Use of amphetamine-type stimulants in the Islamic Republic of Iran, 2004-2015: a review. Eastern Medit Health J. 2017:23:245-56.

47. Asadollahi A, Najafi A. Do risk factors increase measurement of hepatitis $B, C$ signs and HIV-AIDS among middle-aged and older IDUs in southwest Iran? Drugs Alcohol Today. 2019;19(3):230-8.

48. Gheibipour H, Etemad K, Khodakarim S, Sharhani A, Ebrahimi Kebria S. Prevalence and effect factors of HBV among Injection Drug Users in Kermanshah, Iran in 2016 Iranian. J Epidemiol. 2019;15(1):40-6.

49. Moradi G, Jafari S, Zarei B, Mahboobi M, Zavareh FA, Molaei L, et al. Prevalence and risk factors for hepatitis $B$ and hepatitis $C$ exposure in Iranian prisoners: a national study in 2016. Hepatitis Mon. 2019;19:7. 
50. Moradi G, Gouya MM, Azimizan Zavareh F, Mohamadi Bolbanabad A, Darvishi S, Aghasadeghi MR, et al. Prevalence and risk factors for HBV and HCV in prisoners in Iran: a national bio-behavioural surveillance survey in 2015. Trop Med Int Health. 2018;23(6):641-9.

51. Ziaee M, Ebrahimzadeh A, Azarkar Z, Namaei MH, Saburi A, Fereidouni $M$, et al. Seroprevalence and risk factors for hepatitis $b$ in an adult population: the first report from Birjand, South Khorasan. Iran Hepat Mon. 2016;16:9.

52. Kandelouei T, Hosseini SM, Gachkar L, Keyvani H, Davoodbeglou F, Vaezjalali M. Reduction in prevalence of hepatitis B surface antigen among intravenous drug users in Tehran drop-in-centers. Arch Clin Inf Dis. 2013;8:2.

53. Moezzi M, Imani R, Khosravi N, Pourheidar B, Ganji F, Karimi A. Hepatitis B seroprevalence and risk factors in adult population of chaharmahal and Bakhtiari Province in 2013. Hepat Mon. 2014;14:5.

54. Nokhodian Z, Yaran M, Adibi P, Kassaian N, Meshkati M, Ataei B. Seroprevalence of hepatitis B markers among incarcerated intravenous drug users. J Res Med Sci. 2014;19(Special Issue):S13-S6.

55. Ramezani A, Amirmoezi R, Volk JE, Aghakhani A, Zarinfar N, McFarland W, et al. HCV, HBV, and HIV seroprevalence, coinfections, and related behaviors among male injection drug users in Arak. Iran AIDS Care. 2014;26(9):1122-6.

56. Mohammadkhani-Ghiasvand A, Golian-Tehrani S, Modanlu S, Vejdani M, Babaei-Heydarabadi A, Dehghankar L. Investigation of serologic prevalence of HIV and hepatitis B infections and its relationship with behavioral risk factors among drug addicts. Health Syst Res. 2016;12(1):70-6.

57. Alipour A, Haghdoost AA, Sajadi L, Zolala F. HIV prevalence and related risk behaviours among female partners of male injecting drugs users in Iran: Results of a bio-behavioural survey, 2010. Sex Transm Infect. 2013;89(SUPPL. 3):iii41-iii4.

58. Momen-Heravi M, Afzali H, Moosavipanah H. Prevalence of anti HIV, Anti $\mathrm{HCV}$ and HBsAg positive among injection drug users in kashan-Iran. J Clin Immunol. 2013;32:S248.

59. Teimori F, Kariman N, Mansouri F, Rezaei M. Prevalence of high risk behaviours and sexually transmitted infections in women referring to Niloufar drug treatment center, Kermanshah (In Persian). Kermanshah Univ Med Sci J. 2011;15:5.

60. Khosravani A, Sarkari B, Negahban H, Sharifi A, Toori MA, Eilami O. Hepatitis B Infection among high risk population: a seroepidemiological survey in Southwest of Iran. BMC Infect Dis. 2012;12:378.

61. Ziaee M, Sharifzadeh G, Namaee MH, Fereidouni M. Prevalence of HIV and hepatitis B, C, D infections and their associated risk factors among prisoners in Southern Khorasan Province, Iran. Iran J Public Health. 2014;43(2):229-34.

62. Khodadoostan M, Ataei B, Shavakhi A, Tavakoli T, Nokhodian Z, Yaran M. The assessment of hepatitis $B$ seroprevalence in persons with intravenous drug use history in the Isfahan province: community-based study. J Res Med Sci. 2014;19(1):65-8.

63. Nokhodian Z, Yazdani MR, Yaran M, Shoaei P, Mirian M, Ataei B, et al. Prevalence and risk factors of HIV, syphilis, hepatitis B and $C$ among female prisoners in Isfahan, Iran. Hepat Mon. 2012;12(7):92-7.

64. Sofian M, Aghakhani A, Banifazl M, Azadmanesh K, Farazi AA, McFarland W, et al. Viral hepatitis and HIV infection among injection drug users in a central Iranian City. J Addict Med. 2012;6(4):292-6.

65. Khajedaluee M, Babaei A, Vakili R, Valizade N, Shandiz FH, Alavian SM, et al. Sero-prevalence of bloodborne tumor viruses (HCV, HBV, HTLV-I and KSHV infections) and related risk factors among prisoners in Razavi Khorasan province, Iran, in 2008. Hepat Mon. 2016;16:12.
66. Zamani S, Radfar R, Nematollahi P, Fadaie R, Meshkati M, Mortazavi S, et al. Prevalence of HIV/HCV/HBV infections and drug-related risk behaviours amongst IDUs recruited through peer-driven sampling in Iran. Int J Drug Policy. 2010;21(6):493-500.

67. Radfar R, Nematollahi P, Tayeri K. Prevalence of hepatitis B, C and HIV and its related risk factors among addicts admitted to Shahid Irandust Residence Center in 2007 (In Persian). First National Conference on Infection in Substance users (In Persian); Iran 2008.

68. Rahimi-Movaghar A, Razaghi EM, Sahimi-Izadian E, Amin-Esmaeili M. HIV, hepatitis $C$ virus, and hepatitis $B$ virus co-infections among injecting drug users in Tehran. Iran Int J Infect Dis. 2010;14(1):e28-33.

69. Seyed-Alinaghi SA, Kheirandish P, Karami N, Salem S, Shirzad H, Jahani MR, et al. High prevalence of chronic hepatitis B infection among injection drug users in Iran: the need to increase vaccination of adults at risk. Acta Med Iran. 2010;48(1):58-60.

70. Mardani A, Shahsavarani M, Sahami M, Mardani H, Hosseini S, Rahchamandi Z, et al. Prevalence of HBsAg serologic level in drug users of central Ghom province prison in 2004-2005 (In Persian). J Inf Trop Dis Iran. 2009;14:45.

71. Talaie H, Shadnia SH, Okazi A, Pajouhmand A, Hasanian H, Arianpoor $H$. The prevalence of hepatitis $B$, hepatitis $C$ and HIV infections in non-IV drug opioid poisoned patients in Tehran-Iran. Pak J Biol Sci. 2007; 10(2):220-4

72. Asl RT, Eshrati B, Dell CA, Taylor K, Afshar P, Kamali M, et al. Outcome assessment of a triangular clinic as a harm reduction intervention in Rajaee-Shahr Prison. Iran Harm Reduct J. 2013;10:41.

73. Azarkar Z, Sharifzadeh G, Miraki M. Prevalence of HIV, HBV and HCV in Birjand city Prisoners (In Persian). Birjand Univ Med Sci Sci J. 2007;14:2.

74. Imani R, Karimi A, Rouzbahani R, Rouzbahani A. Seroprevalence of HBV, HCV and HIV infection among intravenous drug users in Shahr-e-Kord, Islamic Republic of Iran. East Mediterr Health J. 2008;14(5):1136-41.

75. Khodadadizadeh A, Esmaeili A, Hosseini S, Shabani Z. Prevalence of HIV, $\mathrm{HBV}$ and HCV infection in family members of substance users self-referring to Rafsanjan University of Medical Sciences clinic in 2003 (In Persian). Rafsanjan Univ Med Sci J. 2006;5:1.

76. Pourahmad M, Javady A, Karimi I, Ataei B, Kassaeian N. Seroprevalence of and risk factors associated with hepatitis $B$, hepatitis $C$, and human immunodeficiency virus among prisoners in Iran. Inf Dis Clin Pract. 2007;15(6):368-72.

77. Davoodian P, Dadvand H, Mahoori K, Amoozandeh A, Salavati A. Prevalence of selected sexually and blood-borne infections in Injecting drug abuser inmates of bandar abbas and roodan correction facilities, Iran, 2002. Braz J Infect Dis. 2009;13(5):356-8.

78. Tavakkoli H, Mir-Nasseri MM, Poustchi H, Afshar P, Motalebi MN, Mohammadkhani $A$, et al. Prevalence and risk factors of hepatitis $B$ infection in injection drug users, Tehran (2001-2002). Hepat Mon. 2008;8(1):29-33.

79. Rowhani-Rahbar A, Tabatabee-Yazdi A, Panahi M. Prevalence of common blood-borne infections among imprisoned injection drug users in Mashhad, North-East of Iran. Arch Iran Med. 2004;7(3):190-4.

80. Masaud A, Bagheri E. Study of some opportunistic factors in injecting drug users (In Persian). Tehran Med School J. 1996;54(1):3-6.

\section{Publisher's Note}

Springer Nature remains neutral with regard to jurisdictional claims in published maps and institutional affiliations. 